\title{
Número especial 35 Aniversario del INIFAP en la Revista Mexicana de Ciencias Agrícolas
}

\begin{abstract}
Editorial
De acuerdo con la información del INEGI y AGRICULTURA, el territorio nacional cubre 198 millones de hectáreas, de las cuales, 27.4 millones (14\%) tienen vocación agrícola, 115 millones $(58 \%)$ ganadera y 45.5 millones $(23 \%)$ bosques y selvas. En estas mismas fuentes de información, se menciona que en $79 \%$ de la superficie dedicada a la agricultura se cultiva bajo condiciones de temporal y $21 \%$ bajo alguna modalidad de riego. A lo anterior, hay que agregar la gran diversidad de suelos, climas, cultivos, sistemas de producción y nivel tecnológico en que se desarrollan las actividades agrícolas en nuestro país, dando origen a una equivalente cantidad y diversidad de demandas de tecnología. La respuesta a dichas demandas es factible gracias a la cobertura nacional del Instituto Nacional de Investigaciones Forestales, Agrícolas y Pecuarias (INIFAP), a través de sus 859 investigadores distribuidos en ocho regiones agroecológicas, en las que operan 77 Campos y Sitios Experimentales; adicionalmente, cinco Centros Nacionales de Investigación Disciplinaria y el Centro Nacional de Recursos Genéticos.

A 35 años de haberse constituido, a partir de la fusión de sus antecesores, el Instituto Nacional de Investigaciones Forestales, el Instituto Nacional de Investigaciones Agrícolas y el Instituto Nacional de Investigaciones Pecuarias, el INIFAP continúa esforzándose día a día para cumplir con su Mandato y Misión de atender las demandas tecnológicas de los productores nacionales. Las nuevas tecnologías ofrecen alguna ventaja en productividad y contribuyen en la conservación de los recursos naturales suelo, agua y biodiversidad. Además, se trabaja en el desarrollo de tecnologías con las que se podrán contrarrestar los efectos negativos, directos e indirectos, derivados del calentamiento atmosférico y el cambio climático global.

A partir del 2020 se han realizado una serie de actividades para conmemorar el 35 Aniversario del INIFAP, entre las que se incluyen simposios, videocápsulas, conferencias y publicaciones tecnológicas; sin embargo, no podría faltar una publicación en la que se pudiera presentar algunos ejemplos de logros científicos desarrollados en estas tres y media décadas. Es por esta razón que se tomó la decisión de publicar un número especial de nuestra Revista Mexicana de Ciencias Agrícolas (REMEXCA), en el entendido que los trabajos incluidos son una muestra de nuestro quehacer y que los artículos tuvieron que cumplir con todos los requisitos editoriales que demanda la revista.
\end{abstract}

\section{Dr. Luis Ángel Rodríguez del Bosque}

Dirección general del INIFAP 